\title{
Impact of aerobic exercise capacity and procedure-related factors in lung cancer
}

\section{surgery}

\author{
M. Licker*, J-M. Schnyder\#,ף, J-G. Frey\#, , J. Diaper*, V. Cartier*, C. Inan*, J. Robert+, \\ P-O. Bridevaux ${ }^{\S}$ and J-M. Tschopp ${ }^{f, \star *}$
}

ABSTRACT: Over the past decades, major progress in patient selection, surgical techniques and anaesthetic management have largely contributed to improved outcome in lung cancer surgery. The purpose of this study was to identify predictors of post-operative cardiopulmonary morbidity in patients with a forced expiratory volume in $1 \mathrm{~s}<80 \%$ predicted, who underwent cardiopulmonary exercise testing (CPET).

In this observational study, 210 consecutive patients with lung cancer underwent CPET with completed data over a 9-yr period (2001-2009).

Cardiopulmonary complications occurred in 46 (22\%) patients, including four (1.9\%) deaths. On logistic regression analysis, peak oxygen uptake (peak $V^{\prime} \mathrm{O}_{2}$ ) and anaesthesia duration were independent risk factors of both cardiovascular and pulmonary complications; age and the extent of lung resection were additional predictors of cardiovascular complications, whereas tidal volume during one-lung ventilation was a predictor of pulmonary complications. Compared with patients with peak $V^{\prime} \mathrm{O}_{2}>17 \mathrm{~mL} \cdot \mathrm{kg}^{-1} \cdot \mathrm{min}^{-1}$, those with a peak $\mathrm{V}^{\prime} \mathrm{O}_{2}<10 \mathrm{~mL} \cdot \mathrm{kg}^{-1} \cdot \mathrm{min}^{-1}$ had a four-fold higher incidence of cardiac and pulmonary morbidity.

Our data support the use of pre-operative CPET and the application of an intra-operative protective ventilation strategy. Further studies should evaluate whether pre-operative physical training can improve post-operative outcome.

KEYWORDS: Cardiopulmonary exercise test, lung cancer, lung resection, peak oxygen consumption, post-operative morbidity

T o date, lung resection is the only curative option for the early stages of lung cancer. Overall, perioperative mortality rates range between $2 \%$ and $5 \%$ and the incidence of postoperative cardiopulmonary complications varies between $20 \%$ and $40 \%$, resulting in prolonged hospital stay and increased healthcare costs [1-3]. Although up to $25 \%$ of patients may benefit from surgical resection, in the remaining patients, either the cancer stage is considered too advanced or comorbidities are judged too severe, precluding any benefit in terms of post-operative survival and quality of life [4].

Basically, selection criteria for lung resection entail a stepwise approach with distinct targets, first determining the resectability of the tumour, then assessing the severity of comorbidities and finally questioning the expected functional capacity following lung resection [5-7]. Besides imaging techniques and lung functional investigations, cardiopulmonary exercise testing (CPET) has recently emerged as a noninvasive tool providing valuable diagnostic and prognostic information [8-10]. During incremental physical workload, the physiological reserve of the heart, lungs and skeletal muscles can be quantified by monitoring ECG changes, heart rate and blood pressure responses, respiratory volumes, oxygen consumption and carbon dioxide production, as well as by grading dyspnoea and subjective feelings. Accordingly, interpretation of abnormal results during CPET is helpful for detecting significant coronary artery disease, ventricular or valvular dysfunction, gas exchange or ventilation abnormalities as well as skeletal muscle deconditioning $[8,11]$.

Several prospective studies have demonstrated that limitation of exercise capacity as expressed by peak oxygen uptake (peak $V^{\prime} \mathrm{O}_{2}$ ) or maximal oxygen uptake was strongly predictive of perioperative mortality and cardiopulmonary morbidity [12-15]. Based on these data, CPET has been endorsed by the European Respiratory Society

\section{AFFILIATIONS}

*Dept of Anaesthesiology, Pharmacology and Intensive Care, Faculty of Medicine, University of Geneva,

${ }^{\S}$ Dept of Chest Medicine and Faculty of Medicine, University of Geneva,

**Faculty of Medicine, University of Geneva,

${ }^{+}$Dept of Thoracic Surgery and Faculty of Medicine, University Hospital, Geneva,

${ }^{*}$ Chest Medical Centre ${ }^{f}$ Dept of Internal Medicine, Chest Medical Centre, Montana, and "Dept of Internal Medicine, Hôpital of Sion, Sion, Switzerland.

CORRESPONDENCE

M. Licker

Dept of Anaesthesiology,

Pharmacology and Intensive Care,

Faculty of Medicine

University Hospital of Geneva

rue Gabrielle-Perret-Gentil 4

CH-1211 Geneva

Switzerland

E-mail: licker-marc-joseph@

diogenes.hcuge.ch

Received:

May 042010

Accepted after revision:

Aug 302010

First published online:

Sept 162010 
(ERS) and the European Society of Thoracic Surgery (ESTS) and incorporated in a functional algorithm for the evaluation of candidates for lung resection [16, 17]. These updated guidelines recommend that formal CPET should be performed in all surgical candidates with forced expiratory volume in $1 \mathrm{~s}$ (FEV1) or with diffusing capacity of the lung for carbon monoxide $(D \mathrm{~L}, \mathrm{CO})<80 \%$ of predicted values. Interestingly, this algorithm dates back to the mid-1990s, being tested and subsequently validated in two cohorts of 80 and 135 patients $[18,19]$. Since this pioneering work, advances in surgical techniques and anaesthetic management have led to improved perioperative outcomes, despite increasing proportions of elderly and higher-risk patients [2, 20, 21].

In this study, we retrospectively analysed all lung resection candidates who underwent formal CPET according to the ERS/ESTS guidelines in our institution over the past decade. The main objective was to re-examine predictors of in-hospital cardiac and pulmonary morbidity based on patient comorbidity indices, various parameters of CPET and intra-operative procedure-related factors.

\section{MATERIAL AND METHODS}

\section{Study design and settings}

This was an observational cohort analysis performed on data prospectively collected in patients who underwent lung resection for lung cancer from January 2001 to December 2009 in a tertiary referral hospital ( $\mathrm{n}=243$ patients). The study population included surgical candidates with FEV1 $<80 \%$ pred who underwent CPET according to an algorithm initially proposed by BOLLIGER et al. [19] and updated in 2009 by a task force of the ERS/ESTS $[16,17]$. The study and the database were approved by the local institutional review board and informed consent was waived, given the retrospective analysis of existing documents and the anonymised database. All patients were operated on by a board-certified thoracic surgeon and were managed by the same team of cardiothoracic anaesthetists and chest physicians.

\section{Patients and perioperative management}

Besides clinical evaluation, ECG and laboratory screening, routine pre-operative work-up included pulmonary function tests (SensorMedics; Yonba Linda, CA, USA), lung biopsy, computed tomography (CT) scan and/or positron emission tomography of the chest and abdomen. Patients with abnormal spirometric results (FEV1 $<80 \%$ pred), impaired exercise tolerance or cardiac risk factors, underwent complementary investigations, including CPET and DL,CO.

Symptom-limited CPET was performed on an upright electronically braked cycle ergometer (SensorMedics 2200 SP; SensorMedics). After a 2-min warm-up period at $20 \mathrm{~W}$, an incremental protocol with $20 \mathrm{~W} \cdot \mathrm{min}^{-1}$ workload increases was started. The exercise test was stopped when the patients were exhausted, or at any ECG signs or clinical symptoms of myocardial ischaemia, including a fall in systolic blood pressure. Peak $V^{\prime} \mathrm{O}_{2}$ was expressed in $\mathrm{mL} \cdot \mathrm{min}^{-1} \cdot \mathrm{kg}^{-1}$ body weight and in $\mathrm{mL} \cdot \mathrm{min}^{-1} \cdot \mathrm{kg}^{-1}$ predicted body weight (PBW) [22].

Before surgical incision, antimicrobial prophylaxis was administered (cefuroxime $1.5 \mathrm{~g}$ as a single dose). Lung resection with systematic lymph node sampling was performed through an anterolateral muscle-sparing thoracotomy while the contralateral lung was selectively ventilated with tidal volume $(V \mathrm{~T})$ ranging from 4 to $10 \mathrm{~mL} \cdot \mathrm{kg}^{-1}$ and with variable levels of positive end-expiratory pressure (PEEP; $0-10 \mathrm{cmH}_{2} \mathrm{O}$ ). Fasttrack anaesthetic modalities entailed the administration of short-acting anaesthetic agents and low doses of intravenous opiates, provision of continuous thoracic epidural analgesia, monitoring neuromuscular blockade and goal-directed intravenous fluid loading. All patients were extubated in the operating theatre and were managed over the next $12-24 \mathrm{~h}$ in the post-anaesthesia recovery room before being transferred to the thoracic surgical unit. Post-operative management was standardised with particular emphasis on early feeding with close control of fluid balance, active mobilisation with lung recruitment manoeuvres and provision of multimodal analgesia, including nonsteroidal anti-inflammatory drugs, paracetamol and thoracic epidural blockade. Parenteral morphine was only administered to patients with contraindication for epidural puncture or non-functioning/displaced epidural catheter (10 (4.1\%) out of 243 patients).

\section{Data collection}

The primary composite morbidity rate included operative mortality (death within 30 days of surgery or later if the patient was still hospitalised), as well as cardiovascular complications (myocardial infarction, arrhythmias, congestive heart failure, stroke, thromboembolism or renal dysfunction) and pulmonary complications (atelectasis, pneumonia or acute lung injury (ALI)) as detailed in the appendix and consistent with previous studies $[2,13]$.

Demographic, clinical, surgical and anaesthetic data, as well as pathological stage and perioperative complications, were recorded on a case report form for the index hospitalisation. Respiratory functional data included ergometric parameters (peak $V^{\prime} \mathrm{O}_{2}$, workload, maximal ventilatory capacity and arterial oxygen pressure), baseline spirometric values and the predicted post-operative FEV1 (ppo FEV1) calculated by taking into account the number of open and functional segments removed [5]. Intra-operatively, the following items were also recorded: $V \mathrm{~T}$ during one-lung ventilation, amount of vasopressor drugs, urine output and fluid intake (colloids, crystalloids and blood products). All these data (94 items) were entered into a surgical database and cross-checked for accuracy.

\section{Statistical analysis}

Perioperative clinical, surgical and ergometric characteristics of patients with and without cardiovascular or respiratory complications (or both) were compared with the Chi-squared test for categorical variables (expressed in percentage) and the unpaired t-test (normal distribution) or Wilcoxon rank test (nonGaussian distribution) for continuous variables (all expressed as mean $\pm S D)$.

Variables that had a univariate probability value $<0.20$ or those judged to be clinically important were selected for inclusion in a logistic regression model. To avoid multicolinearity, only one variable was retained in a set of variables with the highest correlation coefficient $(>0.5)$. Independent predictors of cardiovascular and/or respiratory morbidity and factor-adjusted odds ratios with $95 \%$ confidence intervals were calculated. To further assess the reliability of the predictors, 
regression was repeated in 1,000 random bootstrap samples from the original dataset. Given the small number of perioperative deaths (only four cases), mortality was not separately analysed and these cases were included in morbidity analysis according to the type of complications. Model discrimination was evaluated by the area under the receiver operating characteristic (ROC) curve, and calibration was assessed with the Hosmer-Lemeshow goodness-of-fit statistic. All analysis were performed using SPSS software version 14.0 (SPSS, Chicago, IL, USA) and Stata software version 11.0 (Stata Corp, College Station, TX, USA). Statistical significance was specified to a two-tailed type I error ( $p$-value) set below the 0.05 level.

\section{RESULTS}

A total of 210 patients with FEV1 $<80 \%$ pred yielded completed datasets and were included in the study (fig. 1). Table 1 shows the baseline characteristics of patients stratified by peak $V^{\prime} \mathrm{O}_{2}$. Patients with low peak $V^{\prime} \mathrm{O}_{2}\left(<17 \mathrm{~mL} \cdot \mathrm{kg}^{-1} \cdot \mathrm{min}^{-1}\right)$ were more likely to be older, female and hypertensive; they also presented with a higher body mass index (BMI), higher American Society Association (ASA) risk classes, lower FEV1 (pre-operative and predicted post-operative values) and with earlier pathological stages. Rates of coronary artery disease, hypercholesterolaemia, diabetes mellitus, as well as smoking and alcohol status, did not differ significantly among the stratified peak $V^{\prime} \mathrm{O}_{2}$ groups.

Peak $V^{\prime} \mathrm{O}_{2}$ expressed in $\mathrm{mL} \cdot \mathrm{min}^{-1} \cdot \mathrm{kg}^{-1} \mathrm{PBW}$ was higher than peak $V^{\prime} \mathrm{O}_{2}$ expressed in $\mathrm{mL} \cdot \mathrm{min}^{-1} \cdot \mathrm{kg}^{-1}$ absolute body weight $(18.50 \pm$ 5.7 versus $16.0 \pm 5.3 ; \mathrm{p}=0.0003$ ).
As described in table 2, 30-day mortality was $1.9 \%$ and all four deaths occurred in patients with peak $V^{\prime} \mathrm{O}_{2}<17 \mathrm{~mL} \cdot \mathrm{kg}^{-1}$ and were primarily related to cardiovascular complications $(n=3)$ and ALI $(n=1) .46$ patients experienced at least one cardiopulmonary complication (incidence of $22 \%$ ). 36 pulmonary complications occurred in 28 patients (pneumonia, 18 cases; atelectasis, 15 cases; ALI, three cases). 30 cardiovascular complications occurred in 24 patients (arrhythmias, 17 cases; stroke, three cases; acute heart failure, six cases; myocardial infarction, two cases; pulmonary embolism, two cases). 16 patients presented with both cardiovascular and pulmonary complications. Overall, the incidence of complications did not differ in patients undergoing minor or major lung resection $(19.2 \%$ versus $20.5 \%$, respectively; $\mathrm{p}=0.701)$.

In univariate analysis, patients experiencing cardiopulmonary complications had lower pre-operative $V^{\prime} \mathrm{O}_{2}$, they underwent longer and more extensive procedures and required larger doses of vasopressors at the time of surgery; in addition, a higher BMI was associated with a higher incidence of respiratory complications (table 3). In contrast, sex, smoking habits, alcohol consumption, the presence of coronary artery disease, hyperlipidaemia or diabetes mellitus did not differ between groups of patients with or without complications. After adjusting for other perioperative factors by logistic regression, peak $V^{\prime} \mathrm{O}_{2}$ and anaesthesia duration remained independent predictors of cardiovascular and/or pulmonary complications; age and the extent of lung resection (pneumonectomy or bilobectomy) were additional predictors of cardiovascular complications whereas $V \mathrm{~T}$ during one-lung ventilation was an independent risk factor of respiratory complications (table 4).

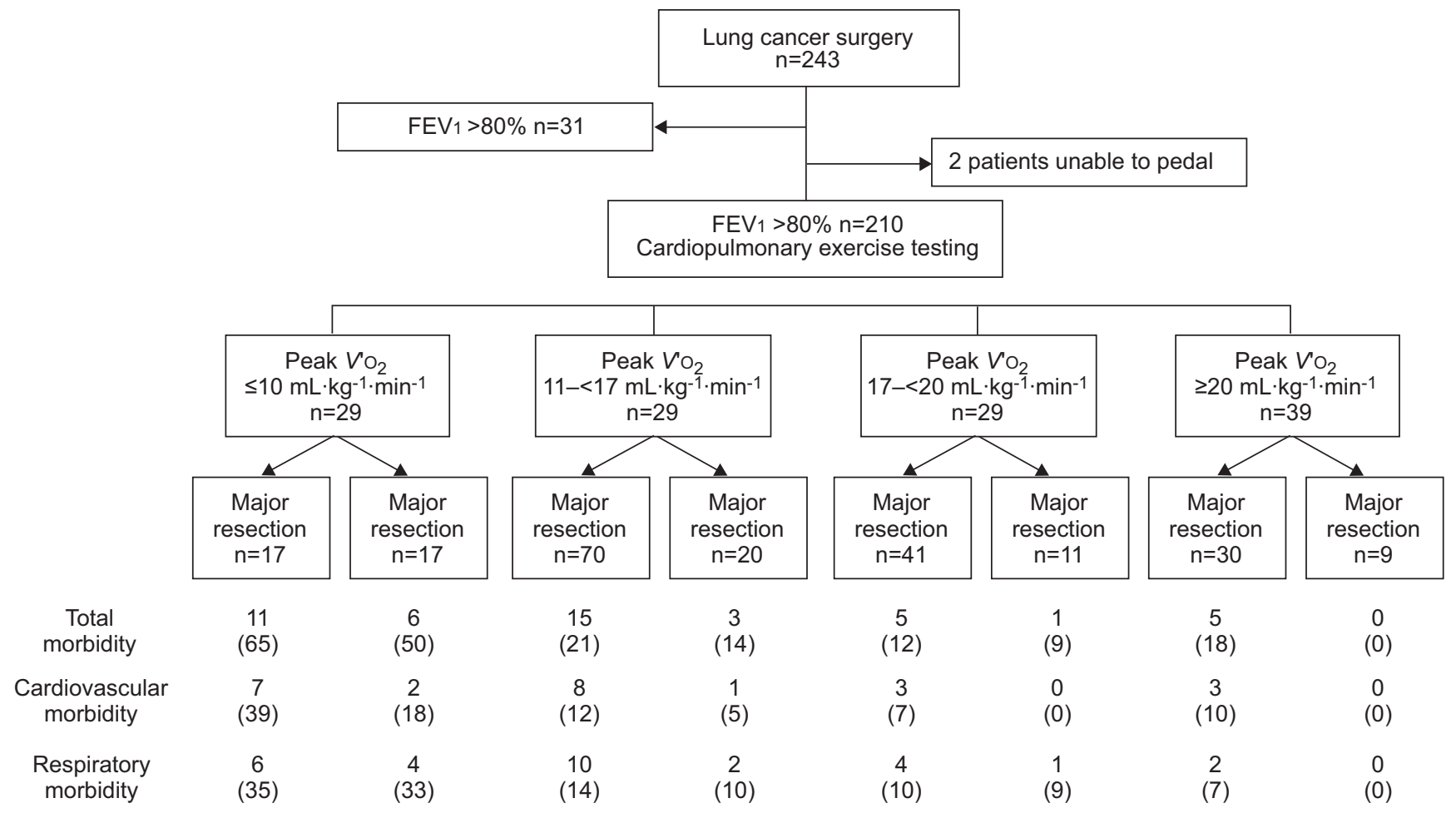

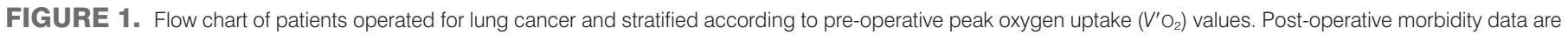
expressed as $n(\%)$. FEV 1 : forced expiratory volume in $1 \mathrm{~s}$; CPET: cardiopulmonary exercise testing. 
TABLE 1 Baseline characteristics stratified by peak oxygen uptake $\left(V^{\prime} \mathrm{O}_{2}\right)$

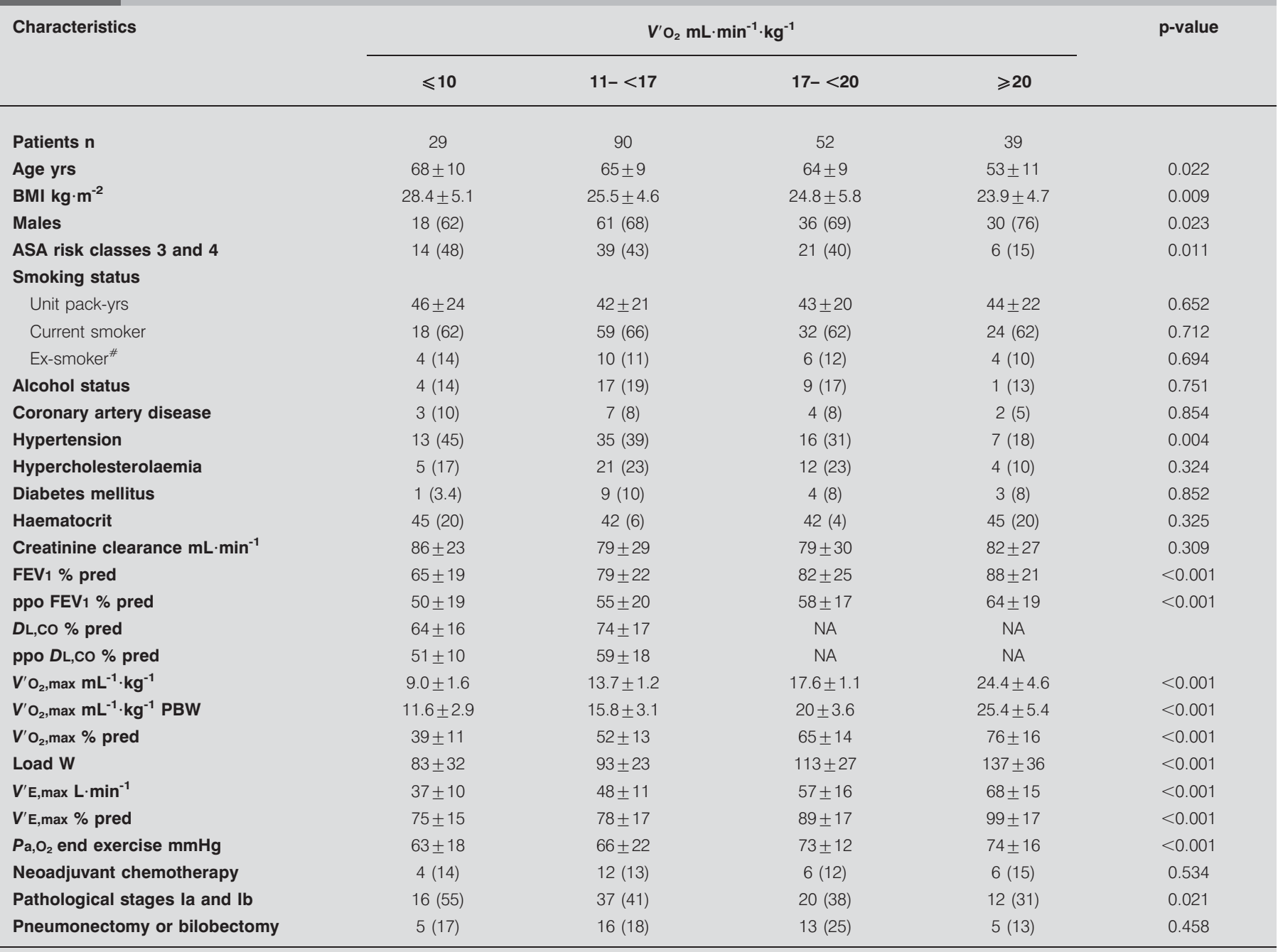

Data are presented as mean \pm SD or $n(\%)$, unless otherwise stated. BMI: body mass index; ASA: American Society Association; FEV 1 : forced expiratory volume in 1 s; ppo: predicted post-operative; $\mathrm{DL}, \mathrm{CO}$ : diffusing capacity of the lung for carbon monoxide; $V^{\prime} \mathrm{O}_{2}$, max: maximal oxygen uptake; PBW: predicted body weight; $V^{\prime} E$,max: minute ventilation during maximal exercise; $\mathrm{Pa}_{1} \mathrm{O}_{2}$ : arterial oxygen pressure; \% pred: \% predicted; NA: not available. ${ }^{\#}:>6$ months smoking cessation.

As detailed in table 5, ROC curve analysis showed that the best cut-off values for peak $V^{\prime} \mathrm{O}_{2}$ to predict cardiac complications were $13.6 \mathrm{~mL} \cdot \mathrm{min}^{-1} \cdot \mathrm{kg}^{-1}$ and $16.2 \mathrm{~mL} \cdot \mathrm{min}^{-1} \cdot \mathrm{PBW}^{-1}$ (c-indices, 0.71 versus 0.74 , respectively; $\mathrm{p}=0.445$ ) whereas for pulmonary complications the best cut-off values were $12.8 \mathrm{~mL} \cdot \mathrm{min}^{-1} \cdot \mathrm{kg}^{-1}$ and $15.8 \mathrm{~mL} \cdot \mathrm{min}^{-1} \cdot \mathrm{PBW}^{-1}$ (c-indices, 0.72 versus 0.65 , respectively; $\mathrm{p}=0.304$ ).

The incidence of cardiovascular and pulmonary complications increased in parallel with the reduction in peak $V^{\prime} \mathrm{O}_{2}$ during exercise testing (fig. 2). Compared with patients with peak $V^{\prime} \mathrm{O}_{2}$ $>17 \mathrm{~mL} \cdot \mathrm{kg}^{-1} \cdot \mathrm{min}^{-1}$, those with a peak $V^{\prime} \mathrm{O}_{2}<10 \mathrm{~mL} \cdot \mathrm{kg}^{-1} \cdot \mathrm{min}^{-1}$ had a four-fold higher incidence of cardiac and pulmonary morbidity.

\section{DISCUSSION}

In this retrospective analysis of surgical candidates with FEV1 $<80 \%$, we demonstrated that markers of pre-operative cardiopulmonary fitness and the duration of anaesthesia were the best predictors of cardiopulmonary complications following lung cancer surgery. In addition, age and the extent of lung resection were also considered independent risk factors of cardiovascular complications, whereas $V$ T during one-lung ventilation was a predictor of pulmonary complications.

Among CPET parameters, peak $V^{\prime} \mathrm{O}_{2}$ values had the best discriminative power to identify the high-risk group of patients. In agreement with previous reports, we confirmed that a peak $V^{\prime} \mathrm{O}_{2}>20 \mathrm{~mL} \cdot \mathrm{kg}^{-1} \cdot \mathrm{min}^{-1}$ is a safe cut-off value for lung resection since no mortality and $<8 \%$ respiratory and cardiac complications occurred above this threshold [13, 23, 24, 25]. In contrast, below $10 \mathrm{~mL} \cdot \mathrm{kg}^{-1} \cdot \mathrm{min}^{-1}$ peak $V^{\prime} \mathrm{O}_{2}$, patients experienced a fourfold higher incidence of cardiovascular and pulmonary complications, compared with surgical candidates presenting peak $V^{\prime} \mathrm{O}_{2}$ values $>20 \mathrm{~mL} \cdot \mathrm{kg}^{-1} \cdot \mathrm{min}^{-1}$. Nevertheless, the use of peak $V^{\prime} \mathrm{O}_{2}$ expressed in $\mathrm{mL} \cdot \mathrm{kg}^{-1}$ may lead to exclusion of obese candidates who are actually fit enough to undergo surgery. As peak $V^{\prime} \mathrm{O}_{2}$, max better correlates with lean body mass than total 
TABLE 2 Clinical and surgical characteristics of patients with and without complications

\begin{tabular}{|c|c|c|c|c|c|c|}
\hline & \multicolumn{2}{|c|}{ Total morbidity } & \multicolumn{2}{|c|}{ Cardiovascular complications } & \multicolumn{2}{|c|}{ Respiratory complications } \\
\hline & Yes & No & Yes & No & Yes & No \\
\hline \multicolumn{7}{|l|}{ Pre-operative period } \\
\hline Patients $\mathrm{n}$ & 46 & 164 & 24 & 186 & 28 & 182 \\
\hline Age yrs & $66 \pm 9$ & $62 \pm 11$ & $69 \pm 9$ & $62 \pm 8^{\#}$ & $65 \pm 9$ & $63 \pm 11$ \\
\hline ASA classes 3 and 4 & $22(48)$ & $58(35)$ & $13(54)$ & $67(36)$ & $15(53)$ & $80(44)$ \\
\hline \multicolumn{7}{|l|}{ Smoking status } \\
\hline Unit pack-yrs & $44 \pm 21$ & $42 \pm 23$ & $45 \pm 23$ & $41 \pm 24$ & $46 \pm 23$ & $43 \pm 21$ \\
\hline Current smoker & $32(69)$ & $101(62)$ & $17(71)$ & $116(62)$ & $20(71)$ & $113(62)$ \\
\hline Ex-Smoker ${ }^{\#}$ & $6(13)$ & $18(11)$ & $3(12)$ & $21(11)$ & $3(11)$ & $21(12)$ \\
\hline Alcohol status & $8(17)$ & $23(14)$ & $4(17)$ & $27(14)$ & $6(21)$ & $25(14)$ \\
\hline Diabetes mellitus & $2(4.3)$ & $15(9.1)$ & $1(4.2)$ & $16(8.6)$ & $2(7.1)$ & $17(9.4)$ \\
\hline FEV $1 \%$ pred & $77 \pm 23$ & $80 \pm 23$ & $78 \pm 22$ & $80 \pm 23$ & $74 \pm 22$ & $80 \pm 23$ \\
\hline ppo FEV $1 \%$ pred & $56 \pm 18$ & $61 \pm 21$ & $55 \pm 16$ & $61 \pm 19$ & $54 \pm 15^{\#}$ & $62 \pm 17$ \\
\hline Hematocrit & $40.3(6.7)$ & $41.9(4.4)$ & $38.5(6.4)^{\#}$ & $42.1(4.6)$ & $41.4(7.5)$ & $41.6(4.6)$ \\
\hline Creatinine clearance $\mathrm{mL} \cdot \mathrm{min}^{-1}$ & $80 \pm 33$ & $84 \pm 25$ & $73 \pm 18^{\#}$ & $85 \pm 27$ & $78 \pm 37$ & $82 \pm 25$ \\
\hline$V^{\prime} \mathrm{O}_{2}, \max \mathrm{mL} \cdot \min ^{-1} \cdot \mathrm{kg}^{-1}$ & $13.0 \pm 4.4^{\#}$ & $16.9 \pm 5.2$ & $13.0 \pm 4.3$ & $16.5 \pm 5.3$ & $15.2 \pm 6.3^{\#}$ & $18.5 \pm 5.6$ \\
\hline$V^{\prime} \mathrm{O}_{2}, \max \mathrm{mL} \cdot \mathrm{min}^{-1} \cdot \mathrm{kg}^{-1} \mathrm{PBW}$ & $15.0 \pm 5.5^{\#}$ & $18.9 \pm 5.6$ & $14.3 \pm 4.0^{\#}$ & $18.6 \pm 5.8$ & $12.7 \pm 4.6^{\#}$ & $16.6 \pm 5.2$ \\
\hline$V^{\prime} \mathrm{O}_{2}$, max $\%$ pred & $50 \pm 17^{\#}$ & $60 \pm 17$ & $50 \pm 14^{\#}$ & $59 \pm 18$ & $49 \pm 20^{\#}$ & $59 \pm 17$ \\
\hline Load $\mathbf{W}$ & $90 \pm 30^{\#}$ & $109 \pm 34$ & $89 \pm 35^{\#}$ & $107 \pm 33$ & $87 \pm 26^{\#}$ & $108 \pm 34$ \\
\hline$V^{\prime} E, \max$ L.min ${ }^{-1}$ & $47 \pm 17^{\#}$ & $54 \pm 16$ & $48 \pm 18$ & $53 \pm 16$ & $46 \pm 15^{\#}$ & $53 \pm 16$ \\
\hline$V^{\prime} E$,max \%pred & $60 \pm 21$ & $65 \pm 17$ & $65 \pm 27$ & $64 \pm 16$ & $56 \pm 12^{\#}$ & $65 \pm 18$ \\
\hline $\mathrm{Pa}, \mathrm{O}_{2}$ end exercice $\mathrm{mmHg}$ & $64 \pm 21$ & $70 \pm 18$ & $58 \pm 24^{\#}$ & $70 \pm 17$ & $67 \pm 20$ & $69 \pm 18$ \\
\hline Fluid $\mathrm{mL} \cdot \mathrm{kg}^{-1} \cdot \mathrm{h}^{-1}$ & $9.6 \pm 5.9$ & $8.8 \pm 3.5$ & $9.4 \pm 7.1$ & $8.9 \pm 3.6$ & $9.1 \pm 4.1$ & $8.9 \pm 4.2$ \\
\hline
\end{tabular}

body weight, several physiologists have recommended the use of height and age in the calculation of predicted peak $V^{\prime} \mathrm{O}_{2}$, particularly when candidates are overweight $[22,26]$.

Interestingly, in the multivariate analysis, ppo FEV1 based on the "segment method" failed to provide additional predictive value for cardiopulmonary complications. Actually, by adopting a functional algorithm for selecting surgical candidates, we excluded most patients with ppo FEV $1<30 \%$. Moreover, in patients with chronic obstructive pulmonary disease (COPD), a "lung volume reduction" effect may take place after resection, providing minimal loss or even improvement in lung function $[27,28]$. Given the prognostic importance of ppo FEV1 regarding long-term quality of life, more accurate estimation of functional segments might have been achieved by using perfusion scintigraphy, quantitative CT or magnetic resonance imaging [29].

Although there is no firmly identified causal mechanism linking a low aerobic capacity with a high-risk profile, one explanation is that "unfit" patients are unable to face the increased surgical stress-induced metabolic demand by mounting an adequate increase in oxygen delivery [11]. Preexisting disturbances in cardiac pumping performances, respiratory function and oxygen utilisation within the skeletal muscles may worsen during the early post-operative period as a result of inadequate pain control, residual effects of anaesthesia, fluid overload, ventilator-induced lung injuries, direct surgical nerve damage, reflex inhibition of diaphragmatic function and muscular fatigue associated with systemic 


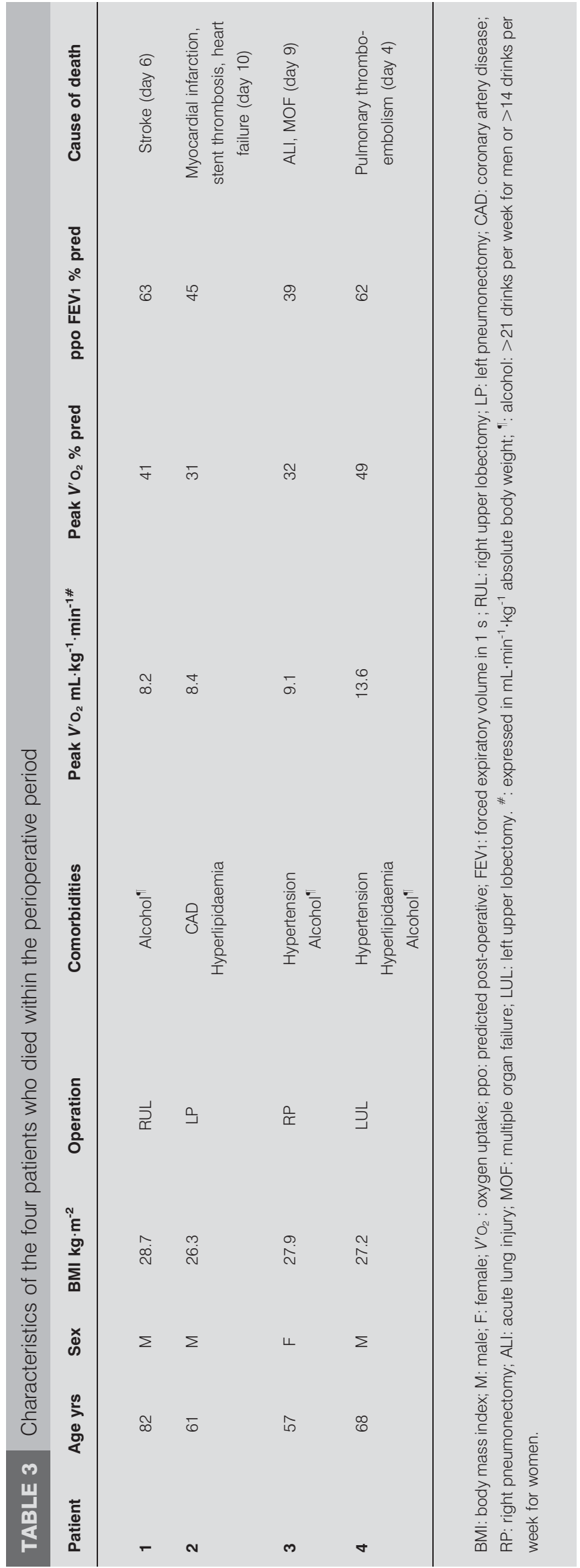

inflammation and enhanced protein catabolism. Indeed, patients with the lowest peak $V^{\prime} \mathrm{O}_{2}$ values $\left(<17 \mathrm{~mL} \cdot \mathrm{kg}^{-1} \cdot \mathrm{min}^{-1}\right)$ presented a higher index of comorbidity as reflected by ASA risk classes, a higher prevalence of arterial hypertensive disease and greater impairments in pulmonary function. Finally, oxidative stress has been shown to accelerate protein breakdown and to trigger nuclear apoptosis in unloaded skeletal muscle, thereby rendering these patients unable to sustain an adequate ventilatory response [30].

Previous investigators have limited their analysis mainly to preoperative clinical and functional parameters that could affect the early post-operative outcome $[13-15,19,25,31]$. In the present study, we assessed $>90$ potential risk factors focusing on patient pre-operative condition but also on intra-operative markers of processes of care. In this regard, prolonged anaesthetic time probably reflected the dual aspects of a complex surgical approach as well as difficulties with anaesthesia emergence and weaning from the ventilator. Extended tissue dissection involving ischaemia-reperfusion injuries would obviously impose larger post-operative metabolic needs and greater loads on the cardiovascular and respiratory systems.

Not surprisingly, we found that age and performing a pneumonectomy or bilobectomy were additional risk factors for the occurrence of cardiac complications. Indeed, excess collagen deposition in the extracellular matrix coupled with a progressive loss of cardiac myocytes by apoptotic cell death are hallmarks of the senescent heart that have been incriminated in the pathogenesis of ventricular dysfunction and atrial fibrillation [32]. Moreover, the pulmonary circulatory system becomes less compliant after extended parenchymal lung resection, resulting in increased right ventricular afterload [33]. However, autonomic nerve injuries occur inevitably when surgical dissection involves the hilar mediastinal structures [34]. Accordingly, the majority of cardiovascular complications consisting of arrhythmias $(8 \%)$ and acute heart failure $(3 \%)$ were probably related to age-associated myocardial remodelling, cardiac autonomic nerve imbalance and greater vulnerability to fluid loading.

Besides markers of cardiopulmonary fitness and the duration of anaesthesia, we found that the intra-operative ventilatory strategy significantly influenced the development of pneumonia, atelectasis and ALI, with larger $V \mathrm{~T}$ being associated with higher operative risk. Consistent with this finding, VT $>7-8 \mathrm{~mL} \cdot \mathrm{kg}^{-1}$ or elevated inspiratory pressure during onelung ventilation have been associated with greater risks to develop ALI and with larger release of cytokines within the lungs and the systemic circulation [35, 36]. Conversely, the application of "physiological" VT $\left(4-7 \mathrm{~mL} \cdot \mathrm{kg}^{-1}\right)$ and external PEEP in patients with healthy lungs undergoing oesophagectomy has been associated with an attenuated systemic proinflammatory response, lower interstitial pulmonary oedema and a better oxygenation index [37]. Performing vital capacity manoeuvre has also been shown to re-expand the collapsed dependent lung areas that develop in almost all anaesthetised patients, whereas moderate levels of PEEP are known to prevent a subsequent fall in functional residual capacity by preventing cyclic opening-closing within pulmonary alveoli and peripheral airways [21,38]. Given the strong body of scientific knowledge related to perioperative ventilator-associated injuries, we have adopted a lung-protective protocol involving small $V \mathrm{~T}$, external 
TABLE 4 Results of logistic regression analysis for different dependent variables

\begin{tabular}{|c|c|c|c|c|c|}
\hline Independent predictor & Coefficient & SEM & OR $(95 \% \mathrm{Cl})$ & p-value & Bootstrap frequency $\%$ \\
\hline \multicolumn{6}{|l|}{ Total morbidity } \\
\hline Duration of anaesthesia & 0.0145 & 0.0041 & $1.015(1.006-1.023)$ & 0.0005 & \\
\hline Peak $V^{\prime} \mathrm{O}_{2}$ in $\mathrm{mL} \cdot \mathrm{min}^{-1} \cdot \mathrm{kg}^{-1}$ & -0.2353 & 0.0546 & $0.79(0.71-0.88)$ & $<0.0001$ & 81 \\
\hline \multicolumn{6}{|l|}{ Cardiovascular complications } \\
\hline Duration of anaesthesia & 0.0143 & 0.0045 & $1.014(1.005-1.024)$ & 0.0016 & 72 \\
\hline Pneumonectomy or bilobectomy & 1.7518 & 0.5674 & $5.76(1.90-17.53)$ & 0.0020 & 71 \\
\hline Peak $V^{\prime} \mathrm{O}_{2} \mathrm{~mL} \cdot \mathrm{min}^{-1} \cdot \mathrm{kg}^{-1}$ & -0.2286 & 0.0768 & $0.80(0.68-0.92)$ & 0.0029 & 69 \\
\hline \multicolumn{6}{|l|}{ Pulmonary complications } \\
\hline Constant & -21.0904 & & & & \\
\hline Duration of anaesthesia & 0.0133 & 0.0042 & $1.013(1.005-1.022)$ & 0.032 & 66 \\
\hline
\end{tabular}

$V^{\prime} \mathrm{O}_{2}$ : oxygen uptake; $\mathrm{VT}_{\mathrm{T}}$ : tidal volume; PBW: predicted body weight.

PEEP and periodical recruitment manoeuvres since March 2003. Over the following 5-yr period, implementation of this "openlung" strategy was associated with a reduced incidence of ALI and atelectasis, along with fewer admissions in intensive care [39].

There are some limitations and strengths of this observational study that should be mentioned. First, although $>90$ items were prospectively collected, we assume some variability in recorded data, unmeasured risk factors and diseases with low prevalence rate (e.g. diabetes mellitus and pulmonary hypertension) that could partly confound the interpretation of the multivariate analysis. Secondly, we obtained peak $V^{\prime} \mathrm{O}_{2}$ data using bicycle exercise that might not be feasible in patients with lower extremities disabilities caused by vascular, neurological

TABLE 5 Areas under the receiver operating characteristic curves and cut-off values of various parameters for the prediction of cardiovascular and pulmonary complications

\begin{tabular}{|c|c|c|c|c|c|c|c|}
\hline & $\begin{array}{l}\text { Area under the } \\
\text { curve }\end{array}$ & $\mathrm{SE}$ & $\begin{array}{l}\text { Lower-upper } \\
\text { bound }\end{array}$ & $\mathrm{p}$-value & Cut-off & Sensitivity \% & Specificity \% \\
\hline$V^{\prime} \mathrm{O}_{2} \mathrm{~kg}^{-1}$ & 0.717 & 0.045 & $0.651-0.777$ & 0.0001 & 12.8 & 51 & 85 \\
\hline$V^{\prime} \mathrm{O}_{2} \mathrm{~kg}^{-1} \mathrm{PBW}$ & 0.710 & 0.045 & $0.643-0.771$ & 0.0001 & 15.8 & 64 & 69 \\
\hline$V^{\prime} \mathrm{O}_{2} \%$ pred & 0.657 & 0.045 & $0.589-0.722$ & 0.0010 & 58 & 75 & 48 \\
\hline \multicolumn{8}{|c|}{ Cardiovascular complications } \\
\hline$V^{\prime} \mathrm{O}_{2} \mathrm{~kg}^{-1}$ & 0.708 & 0.065 & $0.640-0.771$ & 0.0011 & 13.6 & 63 & 72 \\
\hline$V^{\prime} \mathrm{O}_{2} \mathrm{~kg}^{-1} \mathrm{PBW}$ & 0.738 & 0.054 & $0.671-0.798$ & 0.0001 & 16.2 & 75 & 61 \\
\hline$V^{\prime} \mathrm{O}_{2} \%$ pred & 0.633 & 0.061 & $0.562-0.700$ & 0.0029 & 53 & 64 & 61 \\
\hline ASA score & 0.630 & 0.046 & $0.560-0.695$ & 0.0080 & 3 & 79 & 47 \\
\hline ppo FEV $1 \%$ pred & 0.492 & 0.066 & $0.422-0.562$ & 0.9030 & 80 & 29 & 79 \\
\hline$V^{\prime} \mathrm{O}_{2} \%$ pred & 0.616 & 0.066 & $0.544-0.684$ & 0.0169 & 37 & 30 & 95 \\
\hline ASA score & 0.597 & 0.044 & $0.527-0.664$ & 0.0269 & 3 & 73 & 47 \\
\hline ppo FEV1 & 0.545 & 0.051 & $0.480-0.614$ & 0.3716 & 64 & 73 & 50 \\
\hline
\end{tabular}

$V^{\prime} \mathrm{O}_{2}$ : oxygen uptake; PBW: predicted body weight; \% pred: \% predicted; ASA: American Society Association; FEV1: forced expiratory volume in 1 s; ppo: predicted postoperative. 


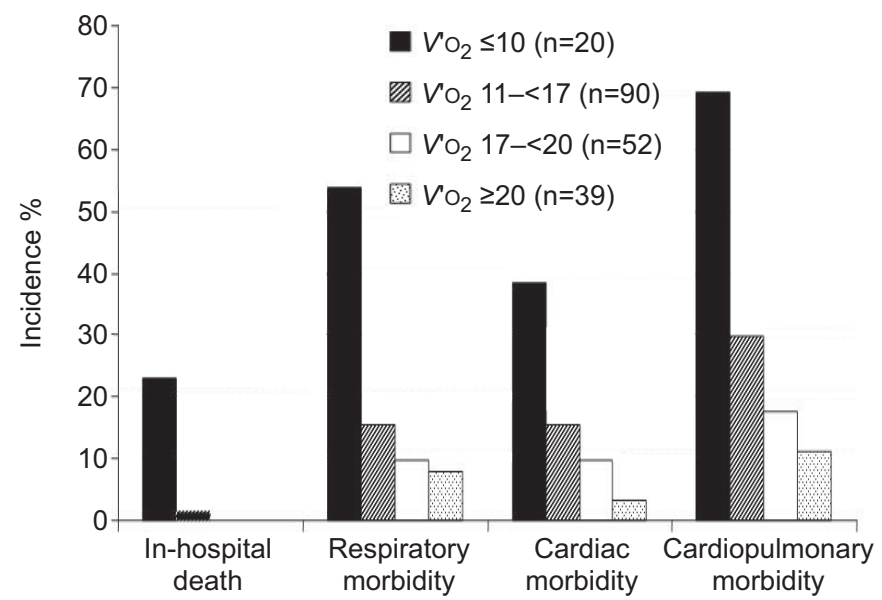

FIGURE 2. Stratification of post-operative outcome according to peak oxygen uptake $\left(V^{\prime} \mathrm{O}_{2}\right)$ values expressed as $\mathrm{mL} \cdot \mathrm{kg}^{-1} \cdot \mathrm{min}^{-1}$. Incidence of cardiac, pulmonary and total cardiopulmonary complications during the hospital stay following surgery.

or orthopedic conditions. In such cases, arm exercise testing should be considered as a suitable alternative [40]. Thirdly our findings obtained in a referral thoracic centre cannot be generalised to nonspecialised units in the absence of standardised clinical pathways. Implementation of bundles of scientifically-based interventions has been shown to improve perioperative outcome. If we compare the current data with those published previously [26], we have witnessed a $25 \%$ reduction in cardiopulmonary morbidity over the past $15 \mathrm{yrs}$; this is probably attributable to the beneficial effects of thoracic epidural analgesia, fluid titration guided by Doppler flow monitoring and protective lung ventilation $[2,39,41]$.

Our selection criteria were less restrictive than in the initial algorithm since 29 patients with peak $V^{\prime} \mathrm{O}_{2}<10 \mathrm{~mL} \cdot \mathrm{kg}^{-1} \cdot \mathrm{min}^{-1}$ were considered suitable candidates for surgery, with 25 survivors, 14 of whom were without any serious complications. The majority of these very high-risk patients presented with early cancer stages IA and IB (55\%) and moderate-to-severe COPD. Although no firm conclusions could be drawn from these encouraging data, some patients deemed inoperable (or at very high-risk) according to their very low peak $V^{\prime} \mathrm{O}_{2}$ values might become eligible for curative surgery, particularly those with acceptable ppo FEV1/ppo DL,CO values ( $>30 \%$ ). Moreover, data support that sublobar resection is a suitable alternative therapy for patients bearing a small sized tumour $(<2-3 \mathrm{~cm})$ whereas minimal deterioration of post-operative FEV1 has been observed in COPD patients after anatomical lobar resection as a result of a "volume reduction" effect [27, 28].

Finally, future trials should question whether improvement in aerobic performances induced by pre-operative physical training may reduce perioperative mortality and morbidity in these high-risk patients. To date, experimental data indicates that short-term intense physical training induces a cardioprotective phenotype similar to ischaemic preconditioning and enhances oxygen extraction from the skeletal muscle by increasing mitochondrial mass, capillary density and oxidative capacity [42, 43]. Preliminary studies in elderly patients with cancer, arterial disease or heart failure confirm the beneficial physiological effects of a short-term supervised training programme, namely an increase in peak $V^{\prime} \mathrm{O}_{2}(+20 \%)$ and in anaerobic threshold $(10 \%)$, a reduction in plasma inflammatory markers and improvement in cardiac function [44-47].

In conclusion, our data strongly support the use of CPET for risk stratification in patients with pre-operative $\mathrm{FEV} 1<80 \%$. Given substantial progress in surgical techniques and anaesthetic management over the last decades, even high-risk patients (peak $V^{\prime} \mathrm{O}_{2}<10 \mathrm{~mL} \cdot \mathrm{kg}^{-1} \cdot \mathrm{min}^{-1}$ ) may be considered for life-saving surgery. According to our results, several riskreducing strategies can be implemented: 1) patient referral to a qualified and experienced thoracic team in order to shorten the time of intervention; 2) application of a protective ventilatory protocol to minimise pulmonary injuries triggered by mechanical ventilation; and 3) considering short-term pre-operative physical training in the "unfit" patients. Further studies are needed to replicate our observations and to question whether improved aerobic capacity achieved by exercise training is associated with better post-operative outcome in the high-risk group.

\section{APPENDIX: MAJOR OUTCOMES \\ Mortality}

Death within 30 days after surgery or for a longer period if the patient was still hospitalised

\section{Cardiovascular}

1) Myocardial infarction: typical rise and fall of creatine phophokinase (CPK) $\left(>120 \mathrm{U} \cdot \mathrm{L}^{-1}\right)$ and MB isoform of creatine kinase $/ \mathrm{CPK} \geqslant 6 \%$ or troponin-I $\geqslant 1.5 \mathrm{ng} \cdot \mathrm{mL}^{-1}$ with at least one of the following criteria: ischaemic symptoms, development of pathological Q waves on the ECG, ST segment elevation or depression $(\geqslant 1 \mathrm{~mm})$ or coronary artery intervention.

2) Arrhythmias: supraventricular and ventricular tachyarrhythmias on ECG causing unstable haemodynamic condition and requiring anti-arrhythmic medications and/or electrical cardioversion.

3) Congestive heart failure: need for sympathomimetic support, diuretics or vasodilators consistent with clinical, haemodynamic (pulmonary artery pressure $\geqslant 15 \mathrm{mmHg}$ ) and radiological evidence of pulmonary congestion.

4) Thrombo-embolism: acute occlusion of pulmonary arteries diagnosed by scintigraphy or angiogram.

5) Stroke: focal neurological deficit (transient or permanent).

6) Renal dysfunction: elevation of serum creatinine $>50 \%$ compared with pre-operative value.

\section{Respiratory}

1) Atelectasis: lobar collapse (chest radiograph), need for continuous positive airway pressure and/or bronchoscopy.

2) Bronchopneumonia: temperature $>38{ }^{\circ} \mathrm{C}$, hyperleukocytosis (neutrophils), new lung infiltration (chest radiograph), positive culture (bronchial secretions or alveolar fluid)

3) Acute lung injury: 1) sudden onset of respiratory distress; 2 ) infiltrates on the chest radiograph consistent with pulmonary oedema; 3 ) impaired oxygenation with an arterial oxygen 
pressure-to-inspired oxygen fraction ratio $<300 \mathrm{mmHg}$; and 4) absence of cardiac insufficiency or fluid overload, based on pulmonary arterial catheterisation, echocardiogram and/or clinical evaluation.

\section{STATEMENT OF INTEREST}

None declared.

\section{REFERENCES}

1 Boffa DJ, Allen MS, Grab JD, et al. Data from The Society of Thoracic Surgeons General Thoracic Surgery database: the surgical management of primary lung tumors. I Thorac Cardiovasc Surg 2008; 135: 247-254.

2 Licker MJ, Widikker I, Robert J, et al. Operative mortality and respiratory complications after lung resection for cancer: impact of chronic obstructive pulmonary disease and time trends. Ann Thorac Surg 2006; 81: 1830-1837.

3 Kates M, Perez X, Gribetz J, et al. Validation of a model to predict perioperative mortality from lung cancer resection in the elderly. Am J Respir Crit Care Med 2009; 179: 390-395.

4 Spiro SG, Tanner NT, Silvestri GA, et al. Lung cancer: progress in diagnosis, staging and therapy. Respirology, 15: 44-50.

5 Colice GL, Shafazand S, Griffin JP, et al. Physiologic evaluation of the patient with lung cancer being considered for resectional surgery: ACCP evidenced-based clinical practice guidelines (2nd Edn). Chest 2007; 132: Suppl., 3161S-177S.

6 Bolliger CT, Koegelenberg CF, Kendal R. Preoperative assessment for lung cancer surgery. Curr Opin Pulm Med 2005; 11: 301-306.

7 van Tilburg PMB, Stam H, Hoogsteden HC, et al. Pre-operative pulmonary evaluation of lung cancer patients: a review of the literature. Eur Respir J 2009; 33: 1206-1215.

8 Palange $\mathrm{P}$, Ward SA, Carlsen $\mathrm{K}-\mathrm{H}$, et al. Recommendations on the use of exercise testing in clinical practice. Eur Respir J 2007; 29 : 185-209.

9 Jones LW, Eves ND, Haykowsky M, et al. Cardiorespiratory exercise testing in clinical oncology research: systematic review and practice recommendations. Lancet Oncol 2008; 9: 757-765.

10 ATS/ACCP statement on cardiopulmonary exercise testing. Am J Respir Crit Care Med 2003; 167: 211-277.

11 Albouaini K, Egred M, Alahmar A, et al. Cardiopulmonary exercise testing and its application. Heart 2007; 93: 1285-1292.

12 Brunelli A. Algorithm for functional evaluation of lung resection candidates: time for reappraisal? Respiration 2009; 78: 117-118.

13 Brunelli A, Belardinelli R, Refai M, et al. Peak oxygen consumption during cardiopulmonary exercise test improves risk stratification in candidates to major lung resection. Chest 2009; 135: 1260-1267.

14 Benzo R, Kelley GA, Recchi L, et al. Complications of lung resection and exercise capacity: a meta-analysis. Respir Med 2007; 101: 1790-1797.

15 Win T, Jackson A, Sharples L, et al. Cardiopulmonary exercise tests and lung cancer surgical outcome. Chest 2005; 127: 1159-1165.

16 Brunelli A, Charloux A, Bolliger CT, et al. ERS/ESTS clinical guidelines on fitness for radical therapy in lung cancer patients (surgery and chemo-radiotherapy). Eur Respir J 2009; 34: 17-41.

17 Brunelli A, Charloux A, Bolliger CT, et al. The European Respiratory Society and European Society of Thoracic Surgeons clinical guidelines for evaluating fitness for radical treatment (surgery and chemoradiotherapy) in patients with lung cancer. Eur J Cardiothorac Surg 2009; 36: 181-184.

18 Wyser C, Stulz P, Soler M, et al. Prospective evaluation of an algorithm for the functional assessment of lung resection candidates. Am J Respir Crit Care Med 1999; 159: 1450-1456.

19 Bolliger CT, Jordan $\mathrm{P}$, Soler $\mathrm{M}$, et al. Exercise capacity as a predictor of postoperative complications in lung resection candidates. Am J Respir Crit Care Med 1995; 151: 1472-1480.
20 Tang SS, Redmond K, Griffiths M, et al. The mortality from acute respiratory distress syndrome after pulmonary resection is reducing: a 10-year single institutional experience. Eur J Cardiothorac Surg 2008; 34: 898-902.

21 Licker M, Fauconnet P, Villiger Y, et al. Acute lung injury and outcomes after thoracic surgery. Curr Opin Anaesthesiol 2009; 22: 61-67.

22 Hansen JE, Sue DY, Wasserman K. Predicted values for clinical exercise testing. Am Rev Respir Dis 1984; 129: S49-S55.

23 BTS guidelines: guidelines on the selection of patients with lung cancer for surgery. Thorax 2001; 56: 89-108.

24 Burke JR, Duarte IG, Thourani VH, et al. Preoperative risk assessment for marginal patients requiring pulmonary resection. Ann Thorac Surg 2003; 76: 1767-1773.

25 Brutsche MH, Spiliopoulos A, Bolliger CT, et al. Exercise capacity and extent of resection as predictors of surgical risk in lung cancer. Eur Respir J 2000; 15: 828-832.

26 Buskirk E, Taylor HL. Maximal oxygen intake and its relation to body composition, with special reference to chronic physical activity and obesity. J Appl Physiol 1957; 11: 72-78.

27 Brunelli A, Al Refai M, Monteverde M, et al. Predictors of early morbidity after major lung resection in patients with and without airflow limitation. Ann Thorac Surg 2002; 74: 999-1003.

28 Edwards JG, Duthie DJ, Waller DA. Lobar volume reduction surgery: a method of increasing the lung cancer resection rate in patients with emphysema. Thorax 2001; 56: 791-795.

29 Ohno Y, Koyama H, Nogami M, et al. Postoperative lung function in lung cancer patients: comparative analysis of predictive capability of MRI, CT, and SPECT. AJR Am J Roentgenol 2007; 189: 400-408.

30 Chopard A, Hillock S, Jasmin BJ. Molecular events and signalling pathways involved in skeletal muscle disuse-induced atrophy and the impact of countermeasures. J Cell Mol Med 2009; 13: 3032-3050.

31 Bobbio A, Chetta A, Internullo E, et al. Exercise capacity assessment in patients undergoing lung resection. Eur J Cardiothorac Surg 2009; 35: 419-422

32 Chen W, Frangogiannis NG. The role of inflammatory and fibrogenic pathways in heart failure associated with aging. Heart Fail Rev 2010; 15: 415-422.

33 Amar D, Burt ME, Roistacher N, et al. Value of perioperative Doppler echocardiography in patients undergoing major lung resection. Ann Thorac Surg 1996; 61: 516-520.

34 Roselli EE, Murthy SC, Rice TW, et al. Atrial fibrillation complicating lung cancer resection. J Thorac Cardiovasc Surg 2005; 130: 438-444.

35 Licker M, de Perrot M, Spiliopoulos A, et al. Risk factors for acute lung injury after thoracic surgery for lung cancer. Anesth Analg 2003; 97: 1558-1565.

36 Schilling T, Kozian A, Huth C, et al. The pulmonary immune effects of mechanical ventilation in patients undergoing thoracic surgery. Anesth Analg 2005; 101: 957-965.

37 Michelet $\mathrm{P}, \mathrm{D}^{\prime}$ Journo $\mathrm{XB}$, Roch $\mathrm{A}$, et al. Protective ventilation influences systemic inflammation after esophagectomy: a randomized controlled study. Anesthesiology 2006; 105: 911-919.

38 Wolthuis EK, Choi G, Dessing MC, et al. Mechanical ventilation with lower tidal volumes and positive end-expiratory pressure prevents pulmonary inflammation in patients without preexisting lung injury. Anesthesiology 2008; 108: 46-54.

39 Licker M, Diaper J, Villiger Y, et al. Impact of intraoperative lungprotective interventions in patients undergoing lung cancer surgery. Crit Care 2009; 13: R41.

40 Myers J, Arena R, Franklin B, et al. Recommendations for clinical exercise laboratories: a scientific statement from the American Heart Association. Circulation 2009; 119: 3144-3161.

41 Diaper J, Ellenberger C, Villiger Y, et al. Transoesophageal Doppler monitoring for fluid and hemodynamic treatment during lung surgery. J Clin Monit Comput 2008; 22: 367-374. 
42 Powers SK, Quindry JC, Kavazis AN. Exercise-induced cardioprotection against myocardial ischemia-reperfusion injury. Free Radic Biol Med 2008; 44: 193-201.

43 Befroy DE, Petersen KF, Dufour S, et al. Increased substrate oxidation and mitochondrial uncoupling in skeletal muscle of endurance-trained individuals. Proc Natl Acad Sci USA 2008; 105: 16701-16706.

44 Bobbio A, Chetta A, Ampollini L, et al. Preoperative pulmonary rehabilitation in patients undergoing lung resection for non-small cell lung cancer. Eur J Cardiothorac Surg 2008; 33: 95-98.
45 Kothmann E, Batterham AM, Owen SJ, et al. Effect of short-term exercise training on aerobic fitness in patients with abdominal aortic aneurysms: a pilot study. Br J Anaesth 2009; 103: 505-510.

46 Wisloff $U$, Stoylen A, Loennechen JP, et al. Superior cardiovascular effect of aerobic interval training versus moderate continuous training in heart failure patients: a randomized study. Circulation 2007; 115: 3086-3094.

47 Jones LW, Eves ND, Mackey JR, et al. Systemic inflammation, cardiorespiratory fitness, and quality of life in patients with advanced non-small cell lung cancer. J Thorac Oncol 2008; 3: 194-195. 